\title{
Three dimensional flow field at confluent fixed-bed open channels
}

\author{
O. Birjukova \\ CEHIDRO, Instituto Superior Técnico, Universidade de Lisboa, Lisbon, Portugal \\ S. Guillen \\ Laboratory of Hydraulic Construction, Instituto Superior Técnico, Lisbon, Portugal \\ École Polytechnique Fédérale de Lausanne, Lausanne, Switzerland \\ F. Alegria \\ Instituto de Telecomunicações, Universidade de Lisboa, Lisbon, Portugal \\ A.H. Cardoso \\ CEHIDRO, Instituto Superior Técnico, Universidade de Lisboa, Lisbon, Portugal
}

\begin{abstract}
River confluences are known for their marked 3D patterns and, due to the complexity of local flow features and bed morphology, they require particular consideration. Although there are studies on the flow structure in junctions of two streams, amore detailed description of the flow patterns is still required. The objective of this work is to contribute to such description at river confluence for concordant bed, where both main and tributary channel beds have the same elevation. For that purpose, a set of experiments with fixed bed under quasi-uniform approach flow conditions was carried out. The experimental facility included a $12 \mathrm{~m}$ long and $1 \mathrm{~m}$ wide main channel, and a $4.5 \mathrm{~m}$ long and $0.15 \mathrm{~m}$ wide tributary channel. The confluence angle was $70^{\circ}$ so as to represent common natural conditions and the discharge ratio between discharges in the tributary and in the main channel was kept constant. An Acoustic Doppler Velocimeter (ADV) with a side-looking configuration was used to measure the three components of flow velocity on a dense grid of measuring points, providing the accurate characterization of the mean flow and second-order velocity moments. The acquired data set constitutes the most refined characterization of river confluence flow structures known to date, due to the adopted temporal and spatial discretization, and may serve for the validation of 3D numerical models of complex confluent flows. Flow dynamics zones typical of confluent beds are present in the studied case. The separation zone limits the effective lateral flow cross-section, and, hence, results in the added acceleration of the mainstream flow near the downstream junction corner. The upward orientated vertical velocities of high magnitude were observed all along the separation zone.
\end{abstract}

\section{INTRODUCTION}

River confluences are of great importance and concern in river engineering, sedimentology or geomorphology due to the complexity of flow interactions as well as to the irregularity in sediment load and bed sediment size. While open-channel junctions are present in many hydraulic systems, few detailed data exist on the flow patterns at confluences, which indicates a need for a new research commitment towards the characterization of the three dimensional flow dynamics in these openchannel regions.

Yet, the study of the flow patterns in junctions of two streams has a relatively long history. After performing theoretical and experimental work in fixed bed channel confluences, Taylor (1944) provided a 1D approach based on momentum and mass conservation equations to calculate the ratio between upstream and downstream water depths. Afterwards, Webber and Greated (1966) conducted laboratory experiments to describe the bulk flow variables at the junction of rectangular open-channels.

Best (1987) identified and described six main distinctive zones/features in river confluences: flow deflection, flow stagnation, flow separation, maximum velocity, shear layers and flow recovery (see Fig. 1). The discharge ratio between the two confluent streams and the junction angle of the river confluence determine the location and extent of the mentioned zones (Mosley 1976, Best 1987).

Weber et al. (2001) characterized the 3D confluence flow patterns based on velocity measure- 
ments with an Acoustic Doppler Velocimeter in a $90^{\circ}$ open-channel junction of equal width with fixed and concordant bed, considering six different discharge ratios. The adopted sampling time was $60 \mathrm{~s}$ at a sampling rate of $10 \mathrm{~Hz}$. The measurement grid consisted of 9 vertical profiles measured at 21 cross-sections, thus covering the entire confluence region. 17 points were measured on each vertical, with the near bed points being more closely spaced. As a result, approximately 2,850 velocity measurement locations for each flow condition were studied.

It is worth mentioning that the previously described studies covered mostly concordant-bed confluences, i.e confluences where both channel beds had the same elevation. However, most natural river confluences are bed discordant, the tributary bed being higher than the main channel bed (Kennedy 1984).

The effects of bed height discordance on the flow pattern of the confluence zone were studied by Biron et al. (1996), Best and Roy (1991). Biron et al. (1996) used two-component Laser Doppler Anemometer (LDA) to measure streamwise, $u$, and vertical, $w$, velocities in a confluence model

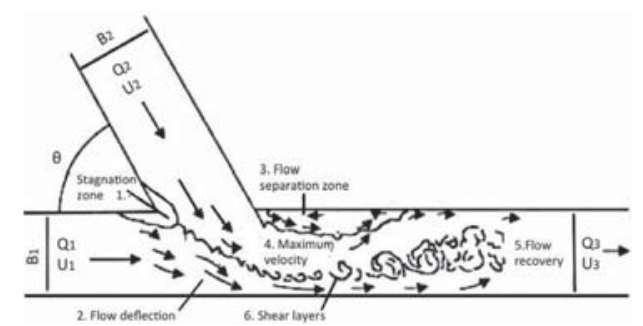

Figure 1. Schematic model of characteristic zones at channel confluences. Modified from Best (1987). with a $30^{\circ}$ junction angle, at 82 vertical profiles along 11 cross-sections, each profile having only 5 measuring points. It is worth mentioning that the aspect ratio (channel width/ flow depth) applied in the study was very low, namely 0.5 and 0.75 in the tributary and main channel and 0.94 in the post confluence channel. Moreover, the amount of measuring points per vertical seems to be insufficient for a detailed characterization of the flow patterns. Nevertheless, bed discordance was found to modify the mainstream flow deflection at the bed and to create important near-bed and water surface level differences at the downstream junction corner. However, Biron et al. (1996) admit that further laboratory studies are required for higher junction angles, mobile bed, higher width/depth ratios, and three-component velocity measurements $(u, v, w)$ in order to assess the influence of bed discordance and bed morphology on the flow dynamics of channel confluences.

Subsequent studies in the river confluences provided the description of the flow structure and bed morphology under mobile bed conditions. Very few laboratory studies can be found in literature (Best 1988, Leite Ribeiro 2010, Leite Ribeiro et al. 2012a, Leite Ribeiro et al. 2012b).

In spite of the existing knowledge on the complex flow structure at junctions of two streams, a more detailed description of the 3D flow patterns is still required. This paper presents an experimental study on the flow patterns of a $70^{\circ}$ openchannel junction with fixed and concordant bed. It was designed to become the reference study i) for the characterization of the flow patterns of the equivalent $\left(70^{\circ}\right)$ discordant-bed confluence as well as ii) for the equivalent mobile bed confluence. The velocity measurements were made by using an Acoustic Doppler Velocimeter over a dense sampling grid consisting of more than 6,000 points

Table 1. Comparison of three experimental studies on concordant and/or discordant fixed bed open-channel confluences.

\begin{tabular}{|c|c|c|c|c|c|}
\hline Literature & Type of set-up & $\begin{array}{l}\text { Junction angle/ } \\
\text { cross-section }\end{array}$ & $\begin{array}{l}\text { Discharge ratio/ } \\
\text { flow regime }\end{array}$ & $\begin{array}{l}\text { Size of measuring grid } \\
\text { (cross-sect/profile/point) }\end{array}$ & $\begin{array}{l}\text { Measured } \\
\text { variables }\end{array}$ \\
\hline $\begin{array}{l}\text { Biron et al. } \\
\text { (1996) }\end{array}$ & $\begin{array}{l}\text { Laboratory LDA } \\
\text { measurements } \\
300 \mathrm{~Hz}\end{array}$ & $\begin{array}{l}30 \% \text { concordant and } \\
\quad \text { discordant beds; } \\
B_{\text {main }} / h_{\text {main }}=0.75 \\
B_{\text {trib }} / h_{\text {trib }}=0.5 \\
B_{\text {posi }} / h_{\text {post }}=0.94\end{array}$ & $\begin{array}{l}Q_{r}=1.23 \\
\quad \text { (concord.) } \\
Q_{r}=1.04 \\
\quad \text { (discord.) }\end{array}$ & $\begin{array}{l}\text { 11/82/5 } \\
\text { Total: } 410 \text { points }\end{array}$ & $u, w$ \\
\hline $\begin{array}{l}\text { Weber et al. } \\
\text { (2001) }\end{array}$ & $\begin{array}{l}\text { Laboratory ADV } \\
\text { measurements } \\
10 \mathrm{~Hz} ; 60 \mathrm{~s}\end{array}$ & $\begin{array}{l}90^{\circ} / \text { concordant beds } \\
B_{p o s t} / h_{p o s t}=3.1\end{array}$ & $0.09<Q_{r}<11.1$ & $\begin{array}{l}\text { 21/189/17 } \\
\text { Total: } \approx 2,850 \text { points }\end{array}$ & $u, v, w$ \\
\hline $\begin{array}{l}\text { Present } \\
\text { study }\end{array}$ & $\begin{array}{l}\text { Laboratory ADV } \\
\text { measurements } \\
100 \mathrm{~Hz} ; 90 \mathrm{~s}\end{array}$ & $\begin{array}{l}70 \% / \text { concordant beds } \\
B_{\text {main }} / h_{\text {main }}=8.8 \\
B_{\text {trib }} / h_{\text {trib }}=1.4 \\
B_{\text {post }} / h_{\text {post }}=10\end{array}$ & $Q_{r}=0.11$ & $\begin{array}{l}\text { 19/334/18 } \\
\text { Total: } 6,012 \text { points }\end{array}$ & $u, v, w$ \\
\hline
\end{tabular}


measured for $90 \mathrm{~s}$ at a given location, at a sampling rate of $100 \mathrm{~Hz}$ and for more realistic aspect ratios $(B / h=8.8,1.4$ and 10 for the main, tributary and postconfluence channels, respectively), thus providing the most comprehensive spatial and temporal resolution measurements known to date. The complete data set will also be used for the validation of 3D computational fluid dynamics codes. Table 1 shows a comparison of three experimental studies at fixed bed open channel confluences for concordant and discordant beds conducted by Biron et al. (1996), Weber et al. (2001) and the one described in the present study.

\section{EXPERIMENTAL FACILITIES AND INSTRUMENTATION}

The experimental campaign was carried out in the $12 \mathrm{~m}$ long, $1 \mathrm{~m}$ wide and $0.5 \mathrm{~m}$ deep, horizontal, rectangular concrete flume of the Hydraulics Laboratory of Instituto Superior Técnico. This flume acted as the main channel and guaranteed quasiuniform flow conditions. A second $4.5 \mathrm{~m}$ long, $0.15 \mathrm{~m}$ wide and $0.5 \mathrm{~m}$ deep flume acted as the tributary channel. This flume was built out of PVC, connected to the main channel $5 \mathrm{~m}$ downstream the main inlet, forming a $70^{\circ}$ confluence angle so as to represent common natural conditions. The water was recirculated from a large reservoir by means of a centrifugal pump. The water discharge at the entrance of the main channel was measured by an electromagnetic flow-meter installed in the hydraulic circuit, while thedischarge in the tributary channel was measured through a calibrated V-notch weir. In order to increase the roughness of the bottom in the main and tributary channels and, hence, guarantee the development of a fully turbulent flow at the entrance of themain channel measurement section, a layer of gravel $\left(d_{50}=6.0 \mathrm{~mm}\right.$ and $\sigma_{D}=2.5$, where $d_{50}=$ median sediment size and $\sigma_{D}=$ sediment gradation coefficient) was placed on the channel bed. The flow discharge ratio, $Q_{r}$, between discharges in the tributary and in the main channel was kept constant $\left(Q_{r}=Q_{t} / Q_{m}=0.114\right.$, where $Q_{t}=0.005 \mathrm{~m}^{3} / \mathrm{s}$ and $Q_{m}=0.044 \mathrm{~m}^{3} / \mathrm{s} ; Q_{m}=$ main channel discharge; $Q_{t}=$ tributary discharge) along the experimental campaign. The discharge ratio was chosen to comply with the experiments performed by Leite Ribeiro (2010), for future comparison purposes.

The flow depth in the main channel, $h_{m}$, was controlled through the downstream tailgate, providing the aspect ratio $B_{m} / h_{m}=8.8\left(h_{m}=0.11 \mathrm{~m}\right.$; $B_{m}=$ main channel width), this way avoiding wall effects in the flume center. Table 2 summarizes the bulk flow variables and channel geometric parameters of the performed study, where $U=$ approach flow velocity, $R e=U h / v=$ approach flow Reynolds number and $\mathrm{Fr}=U /(g h)^{1 / 2}=$ approach flow Froude number.

A side-looking Acoustic Doppler Velocimeter (ADV) was used to measure the three components $(u, v, w)$ of the velocity vector at 6,012 points within the main channel flow as shown in Figure 2. The coordinate system defined for this studyhad the positive $x$-axis oriented in the downstream direction of the main channel. The positive $y$-direction points to the main channel wall adjacent to the channel junction and the positive $z$-axis is upward in the vertical direction. The origin of the coordinates system was the bed at the opposite side (left bank of the main channel) of the upstream junction cross-section (Fig. 3). In order to provide continuous point-by-point measurements of the flow field, an automatic measuring carriage was installed in the main flume. By controling the measuring carriage, it was possible to position the probe in $(x, y, z)$ directions at a precision of $\pm 0.1 \mathrm{~mm}$, thus performing 3D-flow measurements at 19 cross-sections and 334 vertical profiles. 18 points were measured for each vertical profile, i.e. 11 points at a vertical displacement of $2 \mathrm{~mm}$ in the lower $\approx 30 \%$ of the flow depth and 7 points for every $7 \mathrm{~mm}$ in the upper flow region. The sampling frequency was $100 \mathrm{~Hz}$ and the acquisition time per point was $90 \mathrm{~s}$. As it may be seen in Figures 3 and 4 , a dense grid of measuring points was covered.

Seeding particles, composed of silica powder were added to the water whenever necessary to improve the Signal-to-Noise Ratio (SNR) and hence, the quality of the signal. In order to process the signal, the removal of all data samples with communication errors was performed. Namely, all data samples with the average correlation below $70 \%$ or Signal-to-Noise Ratio (SNR) below $10 \mathrm{~dB}$ (Chanson 2008) were ignored. Then the data was "despiked" using the implemented

Table 2. Flow variables and parameters and geometric characteristics in the main and tributary.

\begin{tabular}{llllllllll}
\hline Channel & $\begin{array}{l}Q \\
\left(\mathrm{~m}^{3} / \mathrm{s}\right)\end{array}$ & $\begin{array}{l}h \\
(\mathrm{~m})\end{array}$ & $\begin{array}{l}U \\
(\mathrm{~m} / \mathrm{s})\end{array}$ & $\begin{array}{l}B \\
(\mathrm{~m})\end{array}$ & $\begin{array}{l}R e \\
\left(10^{3}\right)\end{array}$ & $\begin{array}{l}F r \\
(-)\end{array}$ & $\begin{array}{l}B / h \\
(-)\end{array}$ & $\begin{array}{l}d_{50} \\
(\mathrm{~mm})\end{array}$ & $\begin{array}{l}\sigma_{D} \\
(-)\end{array}$ \\
\hline Main channel & 0.044 & 0.114 & 0.39 & 1.00 & 43.4 & 0.36 & 8.8 & 6.0 \\
Tributary channel & 0.005 & 0.114 & 0.29 & 0.15 & 4.9 & 0.27 & 1.4 & 6.0 & 2.5 \\
\hline
\end{tabular}




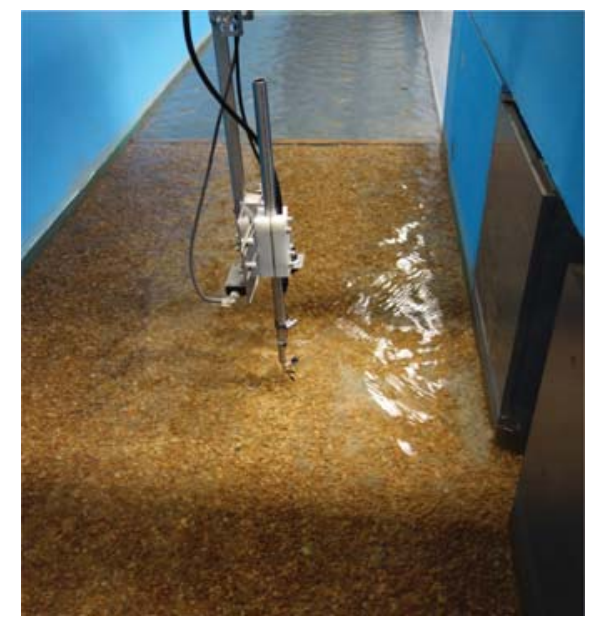

Figure 2. Two channel junction region during the measurement procedure with ADV side-looking probe.

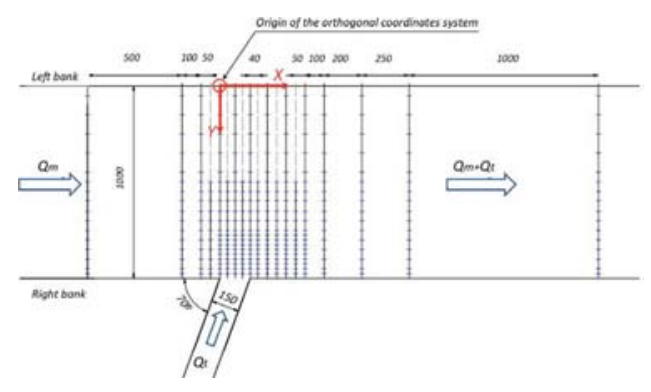

Figure 3. Schematic plan of the confluent channels with the measurement grid. Distances are given in $\mathrm{mm}$.

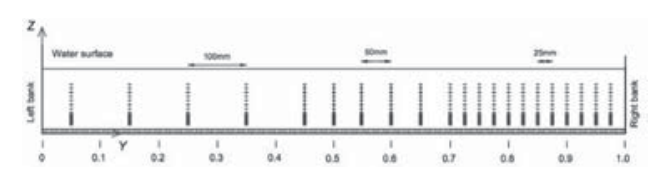

Figure 4. Lateral cross-section of the main channel with the measurement grid.

phase-space thresholding technique (Goring \& Nikora 2002).

\section{RESULTS AND DISCUSSION}

\subsection{Characterization of the approaching flow}

Open channel turbulent flows over a fixed rough bed can be described in two distinct regions, namely the inner region, near the bottom, where the logarithmic velocity distribution is valid and the flow structure is directly dependent on the bed shear stress, $\tau_{0}$, and the outer region, where the influence of $\tau_{0}$ becomes less important. The velocity distribution in the inner region of the boundary layer can be described by the log-law

$\frac{u}{u_{*}}=\frac{1}{\kappa} \ln \left(\frac{z}{k_{s}}\right)+B$,

where $u_{*}$ is the shear velocity, $\kappa$ is the von Kármán constant, usually taken as $0.41, z$ is the vertical coordinate, $k_{s}$ is the characteristic roughness length and $B$ is a function of the Reynolds number, based on the characteristic roughness length and shear velocity and given by $R e_{*}=u_{*} k_{s} / \nu$, where $v$ is water viscosity. For a transitional flow, the value of $B$ varies in the range between 8.5 and 10 , while for hydraulically rough flows it becomes constant, i.e. $B=8.5$. The turbulent flow is considered smooth for $u_{k} k_{s} / \nu \leq 5$ and rough for $u_{*} k_{\star} / \nu \geq 70$.

Figure 5 shows the time-averaged longitudinal velocity profile normalized by the shear velocity, $u_{*}$, obtained in the centerline of the flume, $1.5 \mathrm{~m}$ upstream the two channel junction in order to avoid the possible effect of the tributary flow. The adopted $k_{s}$ value was $d_{65}=7 \mathrm{~mm}$. The adjustment of the log-law presented in equation (1) to the velocity profile in the inner region, namely the logarithmic sublayer, allowed obtaining the shear velocity $u_{*}=0.039 \mathrm{~m} / \mathrm{s}$ and constant $B=8.33$. These values, along with the bed Reynolds number, $u_{*} k_{s} / \nu=272$, are in agreement with the literature for the hydraulically rough boundary layer. The velocity profiles demonstrate that the boundary layer is fully developed.

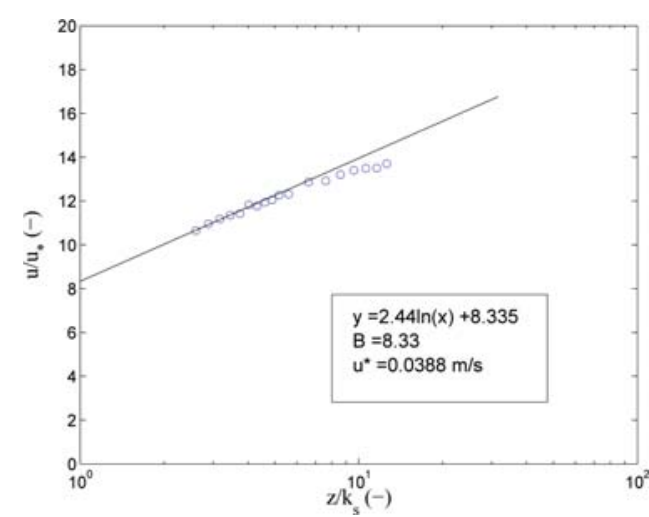

Figure 5. Streamwise mean velocity profile measured in the main channel centerline and at the distance $x=1.5 \mathrm{~m}$ upstream the confluence zone. Experimental data (O) and theoretical approximation line (-). 


\subsection{Longitudinal development of the mean velocities}

\subsubsection{Data presentation}

Velocity measurements are presented through the plots of contour lines for the streamwise, $u$, crosswise, $v$, and vertical, $w$, average values in Figures 6 and 7. Only nine out of nineteen cross-sections were selected for this discussion. The influenceof the tributary flow is discussed by analyzing the five (out of six) flow dynamics regions identified by Best (1987), namely the zones of flow stagnation, deflection, separation, maximum velocity and finally, the flow recovery zone. The discussion of the shear layer region is not included in this paper. All horizontal distances were normalized by the main channel width, $B_{m}$, while vertical distances were normalized by the average flow depth, $h_{m}$. For comparison purposes, streamwise and crosswise velocity contour plots are presented side-by-side, illustrating only the most relevant characteristics of the confluence region, occuring at $0.4 \leq y / B_{m} \leq 1$.

\subsubsection{Approaching flow and stagnation zone}

The contour lines of the streamwise velocity, $u$, at the cross-section located $0.70 \mathrm{~m}$ upstream the upstream junction corner (Fig. 6, a) illustrate the interplay between streamwise velocity patterns with the associated upflow-downflow pairs. Such a flow pattern refers to the existence of circulation cells along the entire channel width (Fig. 6, a). The patterns of the crosswise velocity, $v$, contour lines demonstrate that the sidewall effect is practically negligible, due to the high aspect ratio $\left(B_{m} / h_{m}=8.8\right)$. Higher streamwise velocities are located near the water surface, which is a typical behaviour for the open-channel flows. A second pair of the streamwise and crosswise velocity contourlines measured in the cross-section $x=0.00 \mathrm{~m}$ (Fig. 6, b) shows the presence of a stagnation zone adjacent to the upstream junction corner. From the observation of the contour plots of the vertical velocity component, $w$, it can be stated that there are two zones of downward orientated velocities formed at the entrance of the tributary flow (Fig. 7, b). Thus, the tributary flow acts as an obstacle for the main flow adjacent to the tributary wall region. The downward orientated velocity regions can be seen until the section $x=0.55 \mathrm{~m}$ (Fig. 7, h), while they seem to be displaced towards the center of the flume as the flow proceeds downstream.

\subsubsection{Flow deflection}

From the analysis of the contour lines of the streamwise velocity it can be concluded that the mainstream flow is deflected away from the junction of the tributary as seen in the cross-sections at $x=0.00 \mathrm{~m}$ and $x=0.08 \mathrm{~m}$ (Fig. 6, a, b). Downstreamof the tributary, i.e. at the cross-section $x=0.20 \mathrm{~m}$ (Fig. 6, d) and further downstream, the negative values of the streamwise velocity are associated with the presence of a prolonged separation zone immediately downstream of the tributary, attached to the main channel lateral wall (Biron et al. 1996). Two regions of high streamwise velocities are formed approximately $10 \mathrm{~cm}$ downstream the confluence $(x=0.20 \mathrm{~m})$, that eventually join into one highly accelerated flow zone at $x=0.45 \mathrm{~m}$ (Fig. 6, g).

\subsubsection{Separation zone}

The mentioned separation zone depicted along the junction-adjacent wall results in reduced streamwise mean velocity with the oppositely orientated direction with respect to the mainstream flow and, hence, an upstream flow motion as presented in the cross-sections $x=0.20 \mathrm{~m}$ to $x=0.55 \mathrm{~m}$ (Fig. 6, $\mathrm{d}, \mathrm{h}$ ). Upstream flow motion refers to the existence of recirculation inside the separation zone. This observation is confirmed by the close-to-zero values of the crosswise velocity along the corresponding region. The existence of the separation zone limits the effective lateral flow cross-section, thus creating the conditons for an added acceleration of the mainstream flow. The size of the separation zone for the studied junction angle is considerable, having an approximate maximum length of $\approx 0.6 B_{m}$ and width of $\approx 0.1 B_{m}$. These values can be compared with the corresponding dimensions of the separation zone observed in the study by Biron et al. (1996), where the $30^{\circ}$ junction angledefined the maximum length and width of the confluence zone as $0.32 B_{p}$ and $0.12 B_{p}$, respectively. It is noteworthy that the separation zone is wider closer to the water surface (Weber et al. 2001). Also, there is more recirculation inside the separationzone near the surface as previously mentioned by Biron et al. (1996). Immediately downstream the confluence, at $x=0.20 \mathrm{~m}$ (Fig. 7, d), an upward vertical flow of rather high magnitude is formed. The upward flow is present for both the near-bed and the water surface areas. This observation contrasts with the results by Biron et al. (1996), where no vertical flow was observed immediately downstream from the tributary corner. On the other hand, Weber et al. (2001) describe the upweilling flow in the separation zone as a result of the secondary current flow reflected off the junction-opposite wall. At the distance of approximately $10 \mathrm{~cm}$ from the downstream junction corner (Fig. 7, e), two zones with the upward orientated flow are created-one near the bottom and one closer to the water surface. The upwelling at the junction adjacent wall can be tracked until the cross-section at $x=0.55 \mathrm{~m}$ (Fig. 7, h). 


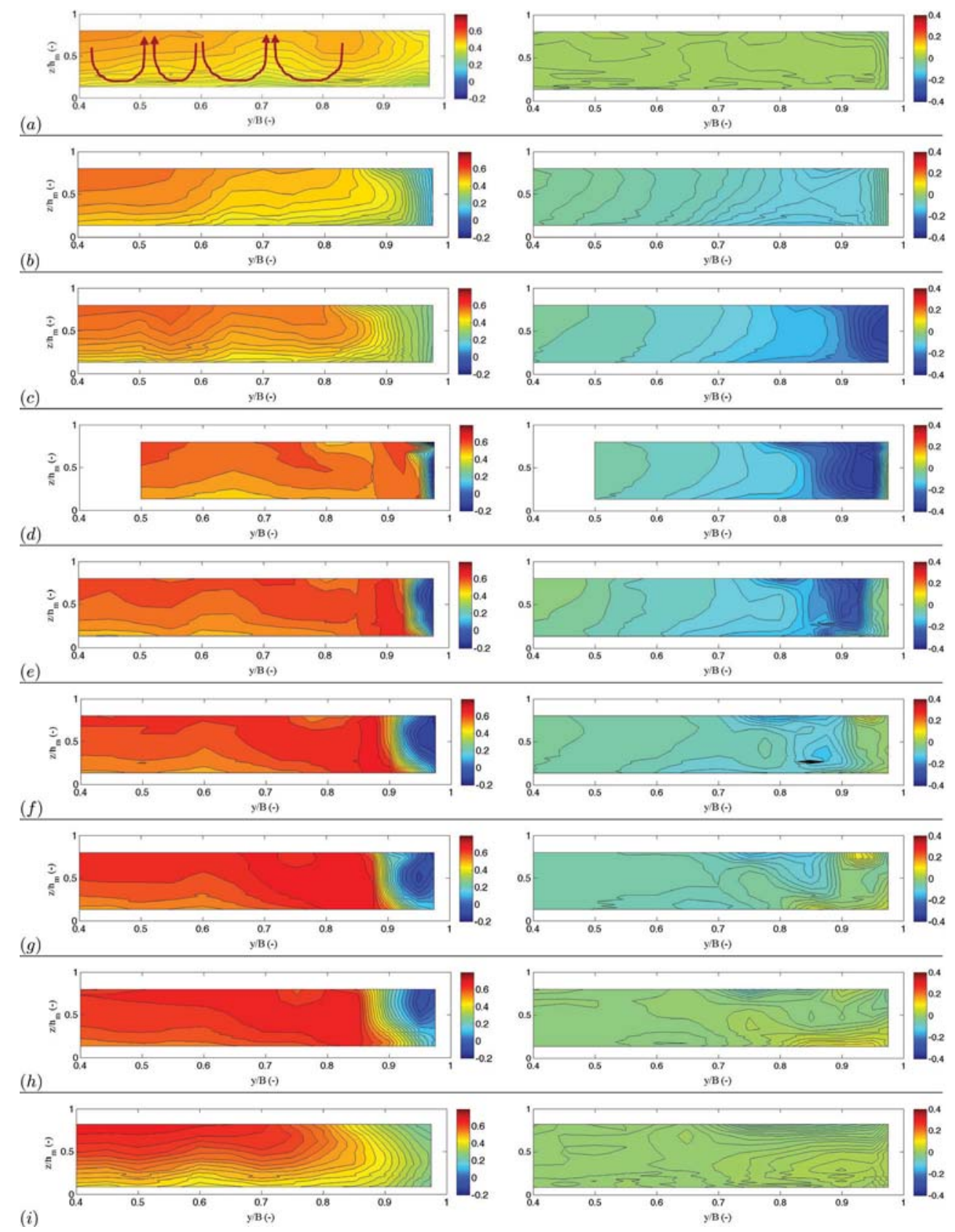

Figure 6. Contour lines of the streamwise, $u$, (left) and crosswise velocities, $v$, (right) in $\mathrm{m} / \mathrm{s}$ at: (a) $x=-0.70 \mathrm{~m}$; (b) $x=0.00 \mathrm{~m}$; (c) $x=0.08 \mathrm{~m}$; (d) $x=0.20 \mathrm{~m}$; (e) $x=0.25 \mathrm{~m}$; (f) $x=0.35 \mathrm{~m}$; (g) $x=0.45 \mathrm{~m}$; (h) $x=0.55 \mathrm{~m}$; (i) $x=2.00 \mathrm{~m}$.

\subsubsection{Maximum velocity zone}

As stated above, the flow acceleration at the channel confluences is not simply the result of the increased discharge due to the added tributary flow, but also a product of the flow separation zone that reduces the available effective area for the total discharge to pass through. Due to the relatively high entrance angle of the lateral flow and a considerable longitudinal and lateral extent of the separation zone, flow acceleration produced in the 


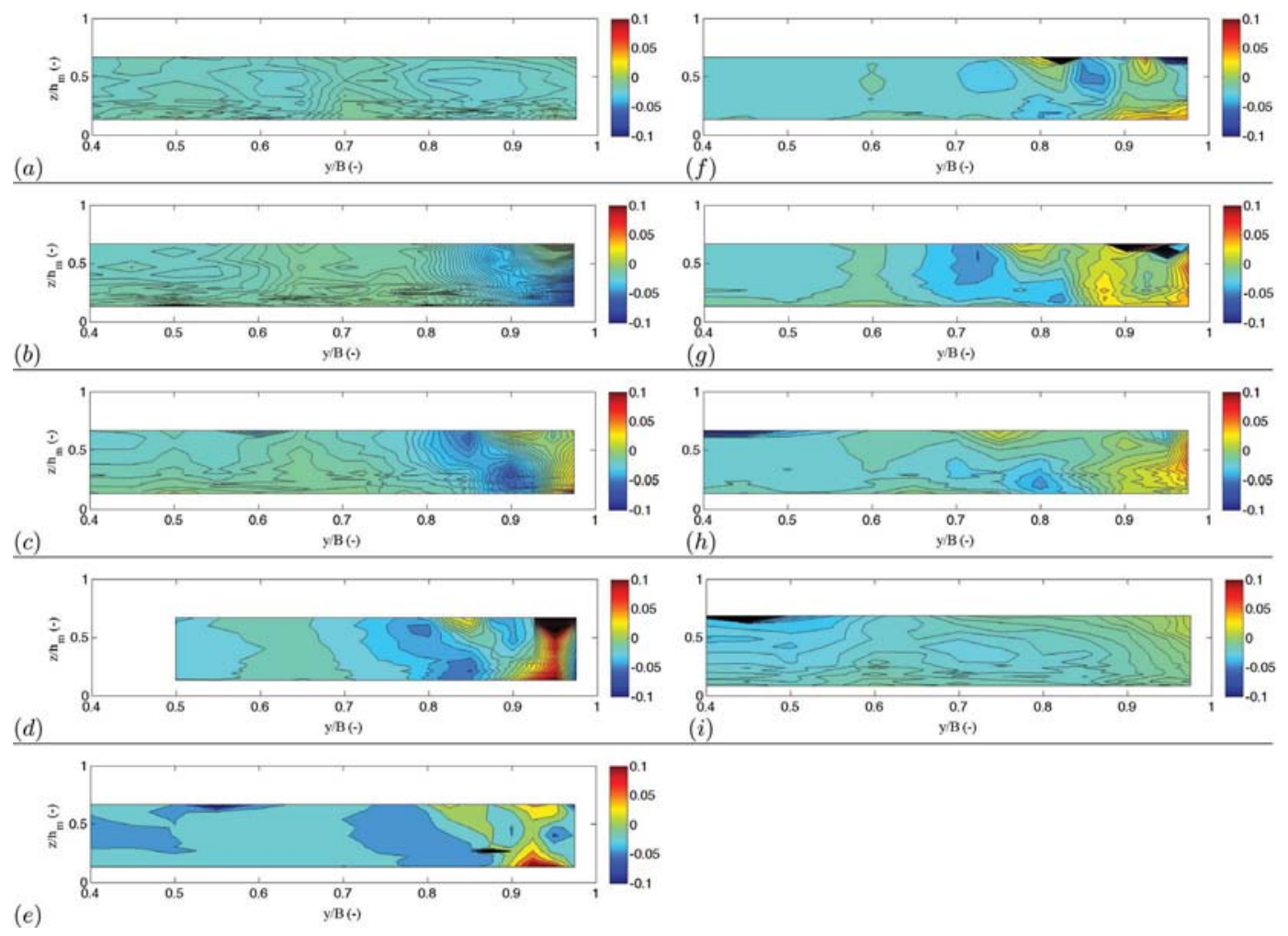

Figure 7. Contour lines of the vertical, $w$, velocity in $\mathrm{m} / \mathrm{s}$ at: (a) $x=-0.70 \mathrm{~m}$; (b) $x=0.00 \mathrm{~m}$; (c) $x=0.08 \mathrm{~m}$; (d) $x=0.20 \mathrm{~m}$; (e) $x=0.25 \mathrm{~m}$; (f) $x=0.35 \mathrm{~m}$; (g) $x=0.45 \mathrm{~m}$; (h) $x=0.55 \mathrm{~m}$; (i) $x=2.00 \mathrm{~m}$.

postconfluence channel was rather significant. The observation of the contourlines of the streamwise velocity at $x=0.55 \mathrm{~m}$ (Fig. $6, \mathrm{~h}$ ) presents rather high velocities of approximately $0.70 \mathrm{~m} / \mathrm{s}$ in the central upper region of the flow, which compares with the streamwise maximum velocities of $\approx 0.50 \mathrm{~m} / \mathrm{s}$ at the undisturbed approach reach upstream of the confluence. The zone of generally high streamwise velocities is located in the region between the crosssections $x=0.20 \mathrm{~m}$ to $x=0.55 \mathrm{~m}$ (Fig. $6, \mathrm{~d}, \mathrm{~h}$ ).

\subsubsection{Flow recovery zone}

At the distance of approximately $2 \mathrm{~m}$ downstream the upstream junction corner (Figs. 6 and 7, i), the mainstream flow starts showing the first flow recovery characteristics. The streamwise velocity adjacent to the tributaty junction wall becomes positivein the downstream direction and the higher velocity zone is mainly concentrated in the central upper region of the main channel. Yet, the typical open-channel flow pattern, streamwise velocities i.e. gradually increasing towards the water surface with the corresponding upflow-downflow pairs, as presented in the cross-section at $x=-0.70$ (Fig. 6, a), is not yet fully developed.

\section{CONCLUSIONS}

The three dimensional flow field at confluent fixed-bed open channels with $70^{\circ}$ junction angle was investigated by performing velocity measurements with a sidelooking Acoustic Doppler Velocimeter. Based on visualization and computation of the average velocity components of the flow throughout the entire confluence region, the main flow features identified by Best (1987) were further characterized. The most important conclusions are summarized next.

- The stagnation zone, which is characterized by the close-to-zero streamwise and crosswise velocities, is formed at the upstream junction corner. The tributary flow acts as an obstacle for the main channel flow, creating two downward orientated velocity fields that are displaced towards the center flume as the flow proceeds downstream.

- The separation zone, characterized by the upstream flow motion and, hence, the flow recirculation, limits the effective lateral flow crosssection, which results in the added acceleration 
of the mainstream flow in the postconfluence channel. The maximum streamwise velocities in the central upper region of the accelerated flow are $\approx 1.4$ times larger than the corresponding velocities at the undisturbed approach flow upstream the confluence. The non-dimensional length and width of the separation zone seem to be of the order of magnitude of that observed by Biron et al. (1996), indicating that the main channel aspect ratio may not influence the relative size of the stagnation zone. This conclusion requires future confirmation.

- The vertical velocities of high magnitude orientated upwards were observed immediately downstream the confluence, all along the separation zone.

Further analysis of the flow patterns including the characterization of the bed shear stress, turbulent kinetic energy and spectral analysis is required.

\section{ACKNOWLEDGEMENTS}

The authors thank the Portuguese Foundation for Science and Technology (FCT) for the financial support of the study through the project PTDC/ ECM/118775/2010.

\section{REFERENCES}

Best, J. (1987). Flow dynamics at river confluences: Implications for sediment transport and bed morphology. Recent Devel. in Fluvial Sedimentology, SEPM Spec. Publ. 39, F.G. Etheridge, R.M. Flores, and M.D. Harvey, eds., 27-35.

Best, J. (1988). Sediment transport and bed morphology at river channel confluences. Sedimentology 35 (3), 481-498.
Best, J. \& A. Roy (1991). Mixing-layer distortion at the confluence of channels of different depth. Nature 350, 411-413.

Biron, P., J. Best, \& A. Roy (1996). Effects of bed discordance on flow dynamics at open-channel confluences. $J$. Hydraulic Engng 122 (12), 676-682.

Chanson, H. (2008). Acoustic doppler velocimetry (adv) in the field and in laboratory: practical experiences. Hydraulic Model Report No. CH70/08, Div. of Civil Engineering, The University of Queensland, Brisbane, Australia, 49-66.

Goring, D. \& V. Nikora (2002). Despiking acoustic doppler velocimeter data. J. Hydraulic Engng 128 (1), 117-126.

Kennedy, B. (1984). On Playfair's law of accordant junctions. Earth Surface Processes and Landforms 9 (2), 153-173.

Leite Ribeiro, M. (2010). Influence of tributary widening on confluence morphodynamics. PhD dissertation. École Polytechnique Fédérale de Lausanne. Lausanne, Switzerland.

Leite Ribeiro, M., K. Blanckaert, A. Roy, \& A. Schleiss (2012a). Flow and sediment dynamics in channel confluences. J. Geophysical Research: Earth Surface 117, $1-19$.

Leite Ribeiro, M., K. Blanckaert, A. Roy, \& A. Schleiss (2012b). Hydromorphological implications of local tributary widening for river rehabilitation. Water Resources Research 48, 1-19.

Mosley, M. (1976). An experimental study of channel confluences. J. Geol 84, 535-562.

Taylor, E.H. (1944). Flow characteristics at rectangular open-channel junctions. In Proc. American Society of Civil Engineers 70(1), pp. 119-121.

Webber, N.B. \& C.A. Greated (1966). An investigation of flow behaviour at the junction of rectangular channels. In Proc. Institute Civil Engineers Vol. 34, London, pp. 321-334.

Weber, L., E. Schumate, \& N. Mawer (2001). Experiments on flow at a 90 degree open-channel junction. $J$. Hydraulic Engng 127 (5), 340-350. 